\title{
Die sosiologie en etiek van beroepsrasionalisering
}

R. Ferreira

Departement Sosiologie

Universiteit van Suid-Afrika

PRETORIA

\author{
P.H. Möller \\ Departement Sosiologie \\ Potchefstroomse Universiteit vir $\mathrm{CHO}$ \\ POTCHEFSTROOM
}

\section{Abstract}

The sociology and the ethics of occupational rationalization

Circumstances, both inside and outside an organization, at times compel the need for occupational rationalization. For the employees who experience the adversity of redundancy, occupational rationalization is defined as a dehumanizing labour practice, due to the fact that individuals are denied the opportunity to be employed. In this article, the Protestant work ethic is utilized in order to evaluate the moral aspects, justifiability. liability, dysfunctions and nonfunctions of occupational rationalization, as well as the simation of redundancy as experienced by rationalized employees. liurthermore, a sociological analysis, wilizing the perspectives of fiunctionalism, critical conflict and interactionism, is given in order 10 shed light on the interpretation. This is done as the implementation of occupational rationalization necessarily raises both sociological and ethical questions. Sociologically, occupational rationalization has a distinct influence on all facels of an individual's social existence and relationships. Ethically, occupational rationalization makes an appeal to morality in terms of the inherent notions of a Protestant work ethic in respect to an individual's love for God, the self and for the neighbour. With regard to the evaluation of occupational rationalization as presented in this article, the aspects of a Protestant work ethic which are raised, and the sociological interpretation of occupational rationalization which is given. this discussion focuses on the ambivalence of rationalization, as well as the future of occupational practice. In conclusion, it is determined that although the practice of occupational rationalization is, at times. a necessity, this process is experienced by the redundant employee as manifest-dysfiunctional, nonfunctional, unethical and in many cases, unjustifiable.

\section{Inleiding}

Verskillende oorsake gee daartoe aanleiding dat die rasionalisering van beroepe 'n wêreldwye verskynsel is. Die verswakking van 'n land se ekonomie asook die transformasie vall organisasies is van die algemeenste oorsake waarom beroeps- 
rasionalisering geïmplementeer word. Die gevolge wat beroepsrasionalisering vir gerasionaliseerdes inhou, word egter dikwels uit die oog verloor - gevolge soos werkloosheid, veranming en annoede, 'n verlies aan selfvertroue en 'n gevoel van vervreemding wat ervaar word. Laasgenoemde vind neerslag in die belewing van magloosheid, betekenisloosheid, normloosheid, isolasie en selfvervreemding.

'n Vraag wat ontstaan en as 'n probleemstelling vir dié artikel geld, is die volgende: Is die inplementering van beroepsrasionalisering in terme van die Protestantse werksetiek asook die taakopdrag wat God aan die mens gegee het (Gen. 1:28; Gen. 3:19), vir gerasionaliseerdes manifes-funksioneel (bedoeld, positief) en eties geregverdig?

Die teoretiese stelling wat as rigtingwyser dien om antwoorde te probeer kry op aspekte wat in die probleemstelling opgesluit is, is die volgende: Die implementering van beroepsrasionalisering is in konflik met die beginsels wat ten grondslag van 'n Protestantse werksetiek lê en daarom ervaar gerasionaliseerdes dit as 'n manifes-disfunksionele, nonfunksionele, onetiese en ongeregverdigde handeling. Die Protestantse werksetiek veronderstel onder meer dat om 'n beroep te beoefen ' $n$ morele verpligting is, dat mense hard moet werk om suksesvol te wees ten einde 'n bestaan te voer. In dié verband word 'n besondere betekenis geheg aan die funksie van 'n beroep as 'n roeping van God en aan die funksie van 'n beroepsloopbaan.

In 'n poging om, teen die agtergrond van die teoretiese stelling, bogenoemde vraag te beantwoord, word aandag aan die volgende geskenk:

* Deurlopend word beroepsarbeid en beroepsrasionalisering aan die hand van aspekte van 'n funksionalistiese, kriticse konflik- en 'n interaksionistiese perspektıef geïnterpreteer om die sosıologıese relevansie daarvan aan te toon.

In die argumentasie vanuit 'n funksionalistiese perspektief word veral gefokus op die destabiliserende en negatiewe gevolge (manifeste disfunksies) en nonfunksies (vervul geen funksie) wat beroepsrasionalisering vir gerasionaliseerdes inlou. Vanuit die hoek van 'n kritiese konflikperspektıef word onder meer gefokus op die rol wat die magselite (klein getal maghebbers wat die lot van andere bepaal) speel in lul beheer oor ekonomiese aktiwiteite, soos die implementering van beroepsrasionalisering. Die interaksionistiese perspektief word ingespan om aan te toon hoe veral gerasionaliseerde werknemers beroepsrasionalisering beleef, die betekenis wat hulle daaraan heg en hoe hulle hul situasie definieer en interpreteer. Op grond van hierdie aspekte kan die outeurs van hierdie artikel hulself in die posisie van gerasionaliseerdes indink en vanuit sodanige situasie beroepsrasionalisering verstaan. Bogenoemde interpretasie is ook eie aan 'n hermeneutiese benadering (vertolkingsbenadering) waarvolgens 'n dialoog 
R. Ferreira \& $P$.H. Moller

tussen vraag en antwoord, tussen sosioloog en situasie gevoer word (vgl. Coetzee, 1989:16-17)

Die verskynsel van bercepsrasionalisering word vervolgens op die volgende wyse bespreek:

* 'n Omskrywing van die begrippe rasionalisering en beroepsrasionalisering word gegee.

* Beroepsrasionalisering word in terme van aspekte van die Protestantse werksetiek geëvalueer. Die idees van Max Weber word nie geevalueer nie, maar word slegs as 'n ontledings- en verwysingsraamwerk gebruik waarvolgens die implementering van beroepsrasionalisering geěvalueer word.

* Die ambivalensie van beroepsrasionalisering word aangetoon omdat dit gelyktydig manifes-funksioneel (bedoeld, positief), manifes-disfunksioneel (bedoeld, negatief) en selfs nonfunksioneel kan wees.

* Die toekoms van beroepsbeoefening word teen die agtergrond van die implementering van beroepsrasionalisering in oënskou geneem. Aandag word spesifiek aan die deburokratisering en die demokratisering van organisasies geskenk.

\section{Die begrippe rasionalisering en beroepsrasionalisering}

Die begrip rasionalisering dui op die proses wat daarop gerig is om groter doeltreffendheid in 'n organisasie te bewerkstellig - 'n proses wat to meer standaardisering en konsekwentheid sal lei. Met rasionalisering word die middele om ' $n$ bepaalde doel te bereik hoër geag as die doel van die organisasie self. Rasionalisering is ' $n$ berekende tipe handeling waarvolgens gepoog word om die wyse waarop 'n organisasiedoelstelling bereik word te verander, ten einde onder andere meer doeltreffendheid te bereik (vgl. Ferreira, 1995:37; Theodorson \& Theodorson, 1970:335-336). Ter wille van groter doeltreffendheid kan 'n organisasie byvoorbeeld deur middel van rasionalisering geherstruktureer word.

In teenstelling met bogenoemde positiewe interpretasie van rasionalisering dui beroepsrasionalisering, vir die doeleindes van dié artikel, op die afskaling en/of afskaffing van poste. On dié rede is beroepsrasionalisering vir die gerasionaliseerde werknemer 'n manifes-disfunksionele en nonfunksionele handeling wat lei tot werkloosheid, veranning, armoede, 'n verlies aan selfvertroue en 'n gevoel van magloosheid, betekenisloosheid, normloosheid, isolasie en selfvervreemding. Boonop word 'n werknemer as gevolg van die handeling deur 'I magselite metodies heheer en gemanipuleer. Hierdie proses ontneem die werknemer van die voorreg om deur middel van die beoefening van 'n beroep dienend te wees.

Koers 6I(t) 1996: $111-42 t$ 413 


\section{Die Protestantse werksetiek en beroepsrasionalisering}

Die Protestantse teoloë Luther en Calvyn het 'n belangrike bydrae tot die Christelike beskouing oor die betekenis van werk gelewer. Vir Luther is werk nie slegs ' $n$ essensiële handeling om daardeur in die basiese behoeftes van die mens te voorsien nie. God se doel met die mens word onder andere ook deur middel van werk bereik. Calvyn huldig die standpunt dat God van die mens verwag om te werk (vgl. Borow, 1964:25; Van der Merwe, 1987:30). In sy The Protestant ethic and the spirit of capitalism lê Max Weber (1991:112) klem op die beoefening van 'n beroep as hy daarop wys dat "... it and it alone disperses religious doubts, and ... provide the certainty of grace".

Met inagneming van bogenoemde standpunte oor die betekenis van werk word beroepsrasionalisering vervolgens aan die hand van die volgende aspekte van die Protestantse werksetiek geëvalueer

* Luther se interpretasie van die konsep beroep.

* Die Calvinistiese beroepsbegrip en die uitverkiesing.

* Die metodiese beheer oor ' $n$ mens se lewe

* Wêreldse asketisme.

\subsection{Luther se interpretasie van die konsep beroep}

Op grond van Luther (vgl. Weber, 1991:84-86, Duvenage, s.a.34-35) se interpretasie van die Bybel behels die heroepshegrip die volgende:

* Dit is 'n lewensnoodwendigheid.

* Dit is liefdesdiens wat ten behoewe van die naaste verrig word

* Dit is diens aan God

Afgesien daarvan dat beroepsbeoefening 'n lewensnoodwendigheid is, word elke beroep beskou as ingestel tot eer van en gehoorsaamheid aan God (vgl. Gen. 3:19). Só geinterpreteer, is 'n beroep ook 'n roeping: God roep 'n mens om 'n bepaalde beroep tot sy eer en tot seen vall die naaste te beoefen. Omdat 'n beroep ook 'n roeping is, beskou 'n Christen die lewe as betekenisvol en vind daarom vreugde in sy/haar beroepsarbeid. Deur vreugde in beroepsarbeid te vind, word God ook op dié wyse gedank en is dit terselfdertyd ' $n$ uitdrukking van medemenslikheid, want die naaste word ook daardeur gedien. Met sodanige houding teenoor werk het die wil en die verantwoordelikheid om te werk ook 'n religieuse betekenis gekry: daaron kan met werk en die betekenis wat dit vir God, 'n Christen en die naaste het, nie onverskillig deur 'n persoon en 'n magselite ongegaan word nie (vgl. Weber, 1991:84-86; Dahm, 1994:1-2; Duvenage, s.a.: 135) 
Binne die konteks van Luther se interpretasie van die konsep beroep, word die implementering van beroepsrasionalisering, veral as dit eensydig deur ' $\mathrm{n}$ magselite toegepas word, 'n sosiologiese en etiese vraagstuk. Soos uit voorafgaande ontleding afgelei kan word, is dit 'n sosiologiese vraagstuk omdat sodanige handeling alle aspekte van die sosiale lewe van 'n gerasionaliseerde persoon beïnvloed, insluitende interpersoonlike en intrapersoonlike verhoudinge. Ook is dit 'n etiese vraagstuk omdat beroepsrasionalisering 'n appèl op liefde teenoor God, die self en die naaste maak. Met beroepsrasionalisering word die religieuse betekenis en morele waarde van werk as 'n roeping verontagsaam.

\subsection{Die Calvinistiese beroepsbegrip en die uitverkiesing}

Calvyn se heroepshegrip (in Weber, 1991:109-112) is religieus-gefundeerd en ten nouste met sy reformatoriese standpunt verweef, naamlik dat werk 'n roeping van God is wat in direkte verband met die uitverkiesing gebring kan word. Die vrug van Goddelike uitverkiesing word onder andere ook verwerklik in die getroue uitvoering van beroepsarbeid. 'n Christen word deur sy beroepsbeoefening geroep om God ook daarmee te verheerlik. Omdat dus in die Goddelike uitverkiesing geglo word, openbaar die geloof sigself in beroepsarbeid. Sukses in beroepsarbeid kan dus ook gesien word as vrug van geloof en uitverkiesing (vgl. Weber, 1991:xiii; Weber, 1976:3; Duvenage, s.a.:40-43).

Die implementering van beroepsrasionalisering is in terme van Calvyn se beroepsbegrip vir gerasionaliseerdes manifes-disfunksioneel asook nonfunksioneel. Dit is ook in konflik met die beginsels wat in die Calvinistiese geloof in die uitverkiesing vergestalt word, want dit strem en demotiveer beroepsbeoefening en beroepsroeping.

\subsection{Die metodiese beheer oor'n mens se lewe}

Die Calvinistiese Christene in Engeland en Europa het sekerheid in God se seen gesoek deur hulle leefwyse streng te beheer en hard te werk. Elke handeling is in die fynste besonderhede nagegaan on daardeur te probeer vasstel of tekens, maar nooit bewyse nie, van God se seên daarin erken kan word (Weber, 1991:109). Die motivering vir prestasie en harde werk gee 'n persoon 'n mate van beheer oor sy eie lewe. Sodanige mate van selfbeheer word as 'n sleutel tot ekonomiese selfstandigheid beskou (vgl. Weber, 1991:115-119; Dahm, 1994:4, 5).

Met beroepsrasionalisering word die beginsel van selfbeheer dikwels verontagsaam. Ook in dié opsig is beroepsrasionalisering vir gerasionaliseerdes 'n manifes-disfunksionele en nonfunksionele handeling. Boonop handel werkgewers dikwels neutraal-affektief (emosieloos) deur 'n kil en berekende houding teenoor werknemers in te neem. Werknemers word deur 'n magselite aan posevalueringstelsels, die meting van en beheer oor eersgenoemdes se beroeps- 
loopbane, roeping en verantwoordelikheid onderwerp. In dié opsig bevind werknemers hulle dus op grond van prestasiemeting in 'n ysterkou van formele rasionaliteit (vgl. Mann, 1983:322; Weber, 1991:xixv). Buitendien protesteer die Christelike beroepsbeskouing teen hierdie beskouing van arbeidsprestasie as ruilwaarde, want dan word die werknemer bloot as 'n produksiefaktor beskou (Duvenage, s.a.:129, 134).

\subsection{Wêreldse asketisme}

In noue wisselwerking en interafhanklikheid met voorafgaande metodiese beheer oor 'n mens se lewe, het 'n lewens- en wêreldbeskouing ontwikkel wat Weber $(1991: 149,154)$ wêreldse asketisme noem. Dié begrip dui daarop dat alhoewel die gelowige Christen besef dat hy/sy in maar nie van die wêreld is nie, hy/sy in wêreldse strukture moet werk en leef (vgl. Weber, 1991:154)

Met 'n wêreldse asketiese lewens- en wêreldbeskouing ontstaan ook 'n pligsbesef en verantwoordelikheidsbesef dat 'n mens vir sy voortbestaan een of ander beroep moet beoefen en andere daardeur tot diens moet wees. 'n Mens word gesosialiseer om te werk ten einde daardeur kulturele doelwitte te bereik. In dié opsig is werk ook 'n sosiaal-wenslike handeling (vgl. Weber, 1991:158; Dunkerley, 1975:1) omdat dit dienend is en tot selfvoorsienendheid bydra. Die implementering van beroepsrasionalisering in organisasies ontneem gerasionaliseerdes van die waarde van werk as 'n sosiaal-wenslike handeling. Ook word gerasionaliseerdes dienooreenkomstig ontneem van die voorreg van naastediens en die sekuriteit van selfvoorsienendheid. Beroepsrasionalisering verhoed dat persone toegang tot institusionele middele kry, naamlik om 'n beroep te beoefen ten einde op 'n legitieme wyse voorafgaande doelwitte te bereik.

\section{Die ambivalensie van beroepsrasionalisering}

Beroepsrasionalisering is ' $n$ ambivalente proses omdat dit vir die werkgewer (magselite) manifes-funksioneel, maar vir die werknemer manifes-disfunksioneel en gewoonlik ook nonfunksioneel is.

\section{* Beroepsrasionalisering as manifes-funksioneel}

Die implementering van beroepsrasionalisering is vir 'n magselite manifesfunksioneel omdat dit noodsaaklik, maar nie noodwendig voldoende is om daardeur organisasiedoelwitte koste-effektiewer te bereik nie. Met hierdie proses lê die klem op doeltreffendheid en berekenbaarheid terwyl die aantasting van werknemers se menswaardigheid nie in ag geneem word nie.

* Beroepsrasionalisering as disfunksioneel en nonfunksioneel

Die implementering van beroepsrasionalisering deur middel van die afskaling en/of afskaffing van poste kan, om verskeie redes, vir gerasionaliseerdes 
disfunksioneel en nonfunksioneel wees omdat 'n persoon se beroepsdoelwitte daardeur nie bereik kan word nie en 'n beroepsloopbaan gevolglik verander en/of becindig is.

\subsection{Uitvloeisels van beroepsrasionalisering}

Hierdie proses is met die beginsels van 'n Protestantse werksetiek in konflik omdat mense wat wil en kan werk nie hulle Goddelike roeping kan vervul deur 'n beroep te beoefen, in hul basiese behoeftes te voorsien asook om daardeur naastediens te lewer nie.

'n Aspek van die Protestantse werksetiek, naamlik dat die beoefening van 'n beroep ' $n$ doel op sigself is (vgl. Weber, 1991:157,159), word met beroepsrasionalisering genegeer en beïnvloed dié handeling ' $\mathrm{n}$ gerasionaliseerde se totale bestaan, veral ten opsigte van die versorgingsfunksie van die gesin. In dié opsig kan 'n gevoel van absolute deprivasie (die algehele ontsegging van lewensmiddele) asook rolkonflik ervaar word wanneer 'n persoon, as gevolg van beroepsrasionalisering, nie aan sy/haar verskillende rolverwagtinge kan voldoen of dit bevredig nie.

In die lig van die voorafgaande bespreking kan beroepsrasionalisering gesien word as destabiliserend en dehumaniserend ondat dit konflik genereer tussen norme wat ekonomiese aktiwiteite reguleer en waardes wat beroepsideale en roepingsbewustheid regverdig. Die gevolge wat die konflik tussen beroepswaardes en ekonomiese norme vir 'n werknemer inhou, is die volgende: 'n gevoel van vervreemding ontstaan by 'n gerasionaliseerde werknemer - 'n gevoel wat neerslag vind in 'n belewing van magloosheid, betekenisloosheid, normloosheid, isolasie en selfvervreemding (vgl. Seeman, 1959:784-790)

- 'n Gevoel van magloosheid (vgl. Seeman, 1959:784-785) word ervaar omdat gerasionaliseerdes dit beleef dat besluite oor die voortsetting van hulle beroep en beroepsloopbaan dikwels eensydig deur iemand anders as hulself, naamlik 'n werkgewer (magselite), geneem word. 'n Buitestaander beslis dus oor hulle beroepstoekoms. Hierdie besluit kom daarop neer dat werknemers nie daartoe in staat is om hulle eie lewens en toekoms te kan belieer nie. In dié verband word die gesagsoewereiniteit van die individu aangetas, genegeer en ondermyn

- 'n Gevoel van helekenisloosheid (vgl. Seeman, 1959:786-787) word beleef deurdat funksionele rasionaliteit toeneem. Funksionele rasionaliteit dui op die herstrukturering van ' $n$ organisasie deur middel van beroepsrasionalisering ten einde organisasiedoelwitte die effektiefste te kan bereik. As gevolg daarvan verloor gerasionaliseerdes hul selfrespek en menswaardigheid, stigmatiseer en 
etiketteer hulle hulself as nutteloos en kan hulle selfs die sin van die lewe, hul afhanklikheid en die voorsienigheid van God bevraagteken.

- 'n Gevoel van normloosheid (vgl. Seeman, 1959:787-788) ontstaan, want 'n mens word gesosialiseer dat dit reg, wenslik en fatsoenlik is om sosiale en kulturele doelwitte ook deur middel van die beoefening van 'n beroep te bereik. As gevolg van beroepsrasionalisering word 'n werknemer verhoed om hierdie doelwitte te bereik (vgl. Merton, 1956:24-50). Wanneer werknemers dus die geleentheid ontsê word om sosiale en kulturele doelwitte as gevolg van beroepsrasionalisering te verwesenlik, dien die waardes geregtigheid, medemenslikheid en naasteliefde dikwels nie as gedragsvoorskrifte waaraan 'n werkgewer voldoen of uitvoering gee nie.

- 'n Gevoel van isolasie (vgl. Seeman, 1959:788-789) word ervaar omdat 'n persoon die implementering van beroepsrasionalisering as ekonomiese uitsluiting beleef. Gestelde doelwitte, byvoorbeeld on 'n inkomste te verdien om te kan oorleef en te ontwikkel, en die middele om dit te bereik, byvoorbeeld die beoefening van ' $n$ beroep, is as gevolg van ekonomiese uitsluiting dus nie meer moontlik nie.

- 'n Gevoel van selfvervreemding (vgl. Seeman, 1959:789-790) ontstaan omdat 'n gerasionaliseerde werknemer sigself as vervreemd beleef deurdat hy/sy die instrument van 'n verplaasde doelwit word, naamlik om deur 'n magselite gerasionaliseer te word. In dié konteks raak werknemers en werkgewers ook vervreemd van mekaar omdat eersgenoemdes instrumente in die hande van laasgenoemdes is en word. Anders gestel: "To be self-alienated ... means to be something less than one might ideally be if the circumstances in society were otherwise ... the inability of the individual to find selfrewarding activities that engage him" (Seeman, 1959:790). In dié verband ervaar gerasionaliseerde werknemers 'n gevoel van relatiewe deprivasie omdat hulle hul situasie met dié van hulle verwysingsgroepe vergelyk. Beroepsgerasionaliseerdes vergelyk hulself dus negatief ten opsigte van ekonomies-aktiewe persone wat 'n beroep beoefen, 'n beroepsloopbaan volg, in hul beroep bevorderingsmoontlikhede ervaar en wie se beroepskundigheid en beroepservaring as nuttig beskou word.

\section{Die toekoms van beroepsbeoefening}

Teen die agtergrond van die voorafgaande bespreking oor en evaluering van beroepsrasionalisering in terme van aspekte van die Protestantse werksetiek en die ambivalensie van beroepsrasionalisering, kan gevra word na wat die toekoms vir beroepsbeoefening dan inhou indien beroepsrasionalisering algemeen in organisasies geimplementeer word. Beroepe het gedurende die afgelope aantal dekades progressief gerasionaliseerd geraak as gevolg van onder andere die 
volgende aspekte: 'n lerinterpretasie van die individu-georiënteerde Protestantse werksetiek, 'n toepassing van rasionele meetinstrumente, byvoorbeeld posgradering- en posevalueringstelsels (Simpson in Ritzer, 1977:391), die klem wat op vooruitgang, produksie en welvaart gelê word. Burokratisering en gesentraliseerde beheer vorm deel van die beroepsrasionaliseringsproses. In die laaste aantal jare het 'n kontra-revolusie, die derasionalisering (nie-afskaffing en nie-afskaling) van werk, veral in sekere ontwikkelde lande soos Swede, momentum begin kry deurdat veral deburokratisering (afskaffing of vervanging van burokrasie) en demokratisering in organisasies gepropageer en geïmplementeer word (Ritzer, 1977:391).

\subsection{Deburokratisering}

Alloewel Weber (vgl. Etzioni-Halevy, 1981:16) 'n toename van burokratisering in die beroepswêreld voorsien het omdat dit, na sy mening, die mees funksionele en effektiefste administratiewe wyse is waarvolgens orde, dissipline, doeltreffendineid en berekenbaarheid in 'n organisasie bereik kan word, bevraagteken sommige mense die geskiktheid en onvennydelikheid van 'n burokratiese organisasievorm (vgl. Ferreira, 1995:217-218). In 'n vinnig veranderende samelewing, soos in Suid-Afrika, kom nuwe probleme voor waar nie die rigiditeit van 'n burokrasie en 'n burokratiese bestuurstyl nie, maar 'n buigsame en aanpasbare organisasiesisteem benodig word.

Met hulle gesagshiërargieë en diktatoriale asook outoritêre manier waarvolgens gesag afgedwing en besluite geneem word, die rigiede toepassing van neergelegde reels en regulasies, onpersoonlike interaksiestrukture asook posevaluering- en bevorderingstelsels het burokrasieë buitendien groter ontwikkel as wat nodig is om werk effektief afgehandel te kry. Die eis om gehumaniseerde werksomstandighede en medeseggenskap in besluitneming is ' $n$ reaksie op onbillike en dehumaniserende arbeidspraktyke (byvoorbeeld die eensydige implementering van beroepsrasionalisering), en 'n aandrang op die deburokratisering en demokratisering van 'n organisasie.

\subsection{Demokratisering}

Die demokratisering van 'n organisasie behels 'n horisontalisering van gesagsverhoudinge en 'n beklemtoning van deelname aan besluitneming (vgl. Esterhuyse, 1994:24). Hiervoor is 'n organisasie-etiek nodig wat berus op die waardes van geregtigheid, medemenslikheid, gelykheid en naasleliefde. 'n Organisasie-etiek wat op bogemelde waardes gebaseer is, dra tot werkkonsensus by (Goffman in Maetens \& Verhoeven, 1995:9, 13). Om arbeid op grond van 'n organisasie-etiek te deburokratiseer en te demokratiseer, moet klem gelê word op aspekte soos die volgende: medeseggenskap in besluitneming, werkkonsensus asook die horisontalisering van gesagsverhoudinge. Ook moet arbeid binne die 
Suid-Afrikaanse konteks meer geafrikaniseer word. Tesame met 'n Eurosentriese individu-georiënteerde aksent, moet dus ook 'n Afrosentriese groepgeoriënteerde aksent deel van 'n nuwe arbeids- en bestuursetos in organisasies uitmaak. Wat die Afrosentriese aksent betref, kan aspekte van die Ubuntu-stelsel (vgl. Mittner, 1995:10-11) met vrug in die deburokratisering en demokratisering van 'n organisasie gebruik word, veral wanneer beroepsrasionalisering ter sprake kom.

* Die Ubuntu-stelsel impliseer naamlik groepsgeoriënteerdheid en 'n kollektiewe bewussyn ('n mens is 'n mens deur ander mense) wat 'n korporatiewe etos in organisasies kan word.

Die Ubuntu-stelsel toon implisiete riglyne ten opsigte van korrekte rasionaliseringsprosedures aan. Die volgende aspekte word deur die Ubuntustelsel betrek:

* 'n Andersoortige bestuurstyl.

* 'n Arbeidsverhoudingestelsel wat op dialoog en konsensusbereiking gebaseer is.

* Die beskerming van menseregte.

\subsection{1 'n Andersoortige bestuurstyl}

'n Bestuurstyl wat met 'n Ubuntu-stelsel gevolg word, behels die volgende: geen permanente wenners of verloorders is in 'n organisasie aanwesig nie (die filosofie van die sterkste oorleef), want die belange van die groep en nie slegs die individu nie, word vooropgestel. Spanwerk of kommunaliteit kom dus aan die orde en onderdanigheid aan 'n magselite (bestuur) - 'n vloerlapkultuur - verdwyn. Werknemers het medeseggenskap aan besluitneming, ook wat die implementering van beroepsrasionalisering betref. Hierdie aspek van bestuurstyl kom daarop neer dat besluitneming deursigtig word en dat geheimhouding verdwyn. Met sodanige bestuurstyl word alle werknemers se belange behartig en bevorder en word meer en beter inligting ook deur middel van terugvoering bekendgemaak. 'n Werknemer word nie meer as bloot 'n homo oeconomicus en produksiefaktor beskou wat deur finansièle en ekonomiese gewin aangespoor word nie. Kritiek kan, mag en moet deur die werknemers op 'n bestuurstyl, op besluite wat geneem, op 'n organisasiekultuur, op bevoordeling, ensovoorts uitgespreek word sonder dat 'n persoon op die een of ander wyse daardeur benadeel of van dislojaliteit beskuldig kan word. Tewens, volgens artikel 14(1) van die Grondwet (200/1993) het elke persoon die reg op vryheid van oortuiging en opinie. Artikel 15 (1) van die Grondwet (200/1993) beskerm ook elke persoon se reg op vryheid van spraak en uitdrukking. 


\subsection{2 'n Arbeidsverhoudingestelsel wat op dialoog en konsensusbereiking gebaseer is}

In noue aansluiting by voorafgaande demokratiese bestuurstyl wat eie aan 'n Ubuntu-stelsel is, behels die arbeidsverhoudingestelsel van Ubuntu die volgende: dat dehumaniserende en onbillike arbeidspraktyke, byvoorbeeld die eensydige implementering van beroepsrasionalisering deur 'n magselite, uit die weg geruim word. Hierdie negatiewe arbeidspraktyke kan reggestel word deur onder andere dialoog, gesamentlike besluitneming op grond van konsensusbereiking (medewete, oorlegpleging, medebeslissing) tussen die twee werkgroepe, naamlik die magselite (werkgewer) en die werknemers. Boonop bepaal artikel $27(1)$ van die Grondwet (200/1993) uitdruklik dat elke persoon die reg op billike arbeidspraktyke het.

\subsubsection{Die beskerming van menseregte}

Met 'n Ubuntu-stelsel word arbeid as 'n mensereg beskou. Beroepsrasionalisering tas dié mensereg aan, veral as dit eensydig deur 'n magselite geïmplementeer word. Tewens, in artikel 23 (1) van die Universal Declaration of Human Rights (vgl. Pojman, 1989:660) word arbeid eweneens as 'n mensereg beskou: "Everyone has the right to work, to free choice of employment, to just and favourable conditions of work and to protection against unemployment "In die modeme denke word dié artikel dikwels beskou as 'n manifestasie van die mens se reg op die maksimum verwesenliking en ontplooiing van sy/haar persoonlikheid. Die reg om te werk word in 'n meerdere mate 'n sentrale tema in die morele uitdaging waarmee 'n landsburger die ekonomiese orde konfronteer (Wiehahn, 1982:444).

Aflangende van die ekonomiese stelsel wat gevolg word (byvoorbeeld sosialisties of kapitalisties), word die reg om te werk egter op verskillende wyses vertolk en toegepas. Reeds in 1948 het die meeste van die wêreld se vryemarklande die Internasionale Arbeidsorganisasie se standpunt onderskryf, naamlik dat die reg om te werk eerder in 'n ekonomiese as in 'n wetlike konteks vertolk moet word. Dié standpunt impliseer dat ekonomiese beleidsrigtings gevolg moet word wat daarop gemik is om voldoende werkgeleenthede vir al die landsburgers te verskaf, met gebruikmaking van alle beskikbare middele, meganismes en hulpbronne om diè doel te bereik. Die reg om te werk kan egter nie as 'il waarborg van wcrk vertolk word wanneer 'n kapitalistiese stelsel gevolg word nie. In die Suid-Afrikaanse konteks word die reg om te werk tersaaklik veral met die implementering van regstellende aksie en die toegang tot opleiding en die moontlikheid tot bevordering binne 'n beroep (vgl. Wiehahn, 1982:444445). 
Die sosiologie en etiek van beroepsrasionalisering

Die aanpassing wat van 'n Eurosentries-georiënteerde magselite vereis word, is dus dat medewete, oorlegpleging en medebes/issing met werknemers aan die orde moet wees. Indien genoemde aspekte van werksetiek bewerkstellig kan word, sal 'n andersoortige verhoudingsisteem tussen 'n magselite en werknemers tot stand kom wat deur inligtinguitruiling, terugvoering en onderhandeling gekenmerk word. 'n Nuwe organisasie-etiek, organisasierealiteit en organisasiekultuur sal dan ook ontwikkel wat werknemerverbruikersvriendelik, menssensitief en humaniserend sal wees, ook wat die implementering van beroepsrasionalisering betref.

\section{Samevatting en gevolgtrekkings}

Swak ekonomiese omstandighede en die transformasie van organisasies is van die belangrikste redes waarom organisasies beroepsrasionalisering implementeer. Beroepsrasionalisering werk egter die volgende teê̈ wat insgelyks aspekte van 'n Protestantse werksetiek is: die reg om 'n beroep te beoefen, medebesluitneming, prestasielewering, selfbeheer, innovasie en kreatiwiteit, pligsbesef en verantwoordelikheidsbesef.

Uit voorafgaande ontledings blyk dit dat die implementering van beroepsrasionalisering, ongeag die noodsaaklikheid daarvan in sekere omstandighede, vir die gerasionaliseerde werknemer 'n manifes-disfunksionele, nonfunksionele, onetiese en ongeregverdigde handeling is, veral as dit eensydig deur ' $n$ magselite toegepas word. Hierdie afleiding word gemaak wanneer beroepsrasionalisering beoordeel word vanuit 'n Protestantse werksetiek, die taakopdrag wat God aan die mens gegee het (Gen. 1:28; Gen. 3:19) en die toekoms van beroepsbeoefening.

Alhoewel werknemers voortdurend aan evaluering onderwerp word, word die werkgewer (magselite) nie daaraan blootgestel nie. Wat laasgenoemdes wel doen, is om voorskrifte en riglyne af te dwing en van evalueringskale (byvoorbeeld Peromnes, Hay Paterson) gebriik te maak waarvolgens die werknemer geëvalueer word. As gevolg van sy ondergeskikte maglose posisie word die werknemer nooit die geleentheid gegun om 'n magselite te evalueer nie. 'n Magselite spring dus die drama en trauma van beroepsrasionalisering vry. In die nuwe demokratiese Suid-Afrika behoort bogenoemde tendens ten opsigte van bestuurstyl te verander en moet 'n magselite eweneens deur werknemers geëvalueer word. Sodanige evaluering kan in sommige gevalle moontlik die volgende aan die lig bring: "In a hierarchy every employee tends to rise to his level of incompetence" (Peter \& Hull, 1979:22).

Deur kritiek op veral die eensydige implementering van beroepsrasionalisering te lewer asook op die verskeidenheid gevolge te wys wat die handeling vir gerasionaliseerdes inhou, dien 'n sosioloog ook as die sosiale gewete van andere. 
Daarom kon in die voorafgaande ontleding van die proses van rasionalisering nie agter die dekmantel van waardevryheid geskuil word nie, want dan sou die outeurs wetenskaplike verantwoordelikheid gerieflikheidshalwe ontduik het.

\section{Bibliografie}

BOROW, H. 1964. Man in a world at work. Boston : Houghton Mifflin

COETZEE, J.K. 1989. The quest for a more human society - a different sociology? Grahamstown : Rhodes University.

DAHM, K.-W. 1994 The religious conditions of the capitalist economic attitude - Max Weber's thesis. (Paper delivered on 4 September 1994 at the PU for CHE.) Potchefstroom. 9 p. (Unpublished.)

DUNKERLEY, D. 1975. Occupations and society. London : Routledge \& Kegan Paul.

DUVENAGE, B. s.a. Beroepsarbeid in die lig van die gereformeerde etiek. Potgietersrus : Môrester-drukkery.

ESTERHUYSE, W. 1994. Implikasies van die prosesse van transformasie vir die universiteitswese in Suid-Afrika. Koers, 59(1):19-36.

ETZIONI-HALEVY, E. 1981. Social change: The advent and maturation of modern society. London : Routledge \& Kegan Paul.

FERREIRA, $R$ 1995. Die invloed van rasionalisering op die beroepsmobiliteit van offisiere in die Suid-Afrikaanse Leer: 'n sosiologiese ondersoek. Potchefstroom : PU vir CHO. (Proefskrif - Ph.D.)

MAETENS, D. \& VERHOEVEN, J.C. 1995. The problem of social order and morality: Comparing the views of Erving Goffman and Niklas Luhmann. (Paper delivered at the 13th World Congress of Sociology at the University of Bielefeld on 20 July 1995.) Bielefeld 22 p. (Unpublished.)

MANN, M. 1983. Rationality. (In Mann, M., ed. The Macmillan student encyclopedia of sociology. London: Macmillan p. 321-322.)

MERTON, R.K. 1956. The social-cultural environment and anomie. (In Witmer, H.L \& Kotinsky, R., eds New perspectives for research on juvenile delinquency. Washington, D C. : U.S. Department of Health Education and Welfare. p 24-50.)

MITTNER, M. 1995. Ubumm - bestuurstyl van die toekoms? Finansies \& Tegniek, 47(26):10-11.

PETER, L.J. \& HULL, R. 1979. The Peter principle. London : Pan Books.

POJMAN, L.P. 1989. Ethical theory: Classical and contemporary readings. Belmont : Wadsworth.

RITZER, G. 1977 Working, conflict and change. Englewood Cliffs, N.J. . Prentice-Hall.

SEEMAN, M. 1959. On the meaning of alienation. American Sociological Review, 24(1) 783-791

SUID-AFRIKA 1993 Grondwet van die Republiek van Suid-Afrika, no 200 van 1993. Pretoria : Staatsdrukker.

THEODORSON, G.A \& THEODORSON, A.G 1970 A modern dictionary of sociology New York: Crowell.

VAN DER MERWE, L. 1987. Die mens en werk: 'n sosiologiese beskouing. SuidAfrikaanse Tydskrif vir Sosiologie, 18(1):30-35

WEBER, M 1976. The Protestant ethic and the spirit of capitalism. 2nd ed. London George Allen \& Unwin

WEBER, M. 1991. The Protestant ethic and the spirit of capitalism 21 st ed. London : Harper Collins. 
Die sosiologie en etiek van beroepsrasionalisering

WIEHAHN, N.E. 1982. Die volledige Wiehahn-verslag. Dele l-6 en die Witskrif op elke deel. Johannesburg . Lex Patria. 